\title{
Hipólito José da Costa e as ideias econômicas d'O Correio Braziliense
}

\author{
Hipólito José da Costa and the economic ideas in Correio Braziliense
}

\section{Milena Fernandes Oliveira}

Doutora em Economia Aplicada-História Econômica

Professora do Instituto de Economia da Universidade Estadual de Campinas milena.foliveira@gmail.com

Resumo: Este trabalho pretende um estudo sobre alguns dos artigos escritos por Hipólito José da Costa (1774-1823) e veiculados no Correio Brasiliense entre 1808 e 1823. O recorte temático visa a uma relação entre a concepção de nação e as ideias econômicas de Hipólito da Costa. Mobilizando suas várias experiências, como a viagem à Filadélfia em 1798, a prisão nos cárceres da Inquisição Portuguesa entre 1804 e 1805 e a formação na Universidade de Coimbra entre 1795 e 1797 , Hipólito da Costa fundou o Correio Braziliense em 1808. O periódico, que circulou entre 1808 e 1823, acompanhou os principais momentos da política externa do império luso-brasileiro, desde a chegada a Coroa Portuguesa até a Independência do Brasil. Em 1820, com a Revolução do Porto e a proposta de recolonização do Brasil, Hipólito passou a defender um projeto de nação sui generis para o Brasil, objeto de discussão desse trabalho.

Palavras-chave: Correio Braziliense, nação, ideias econômicas.

\begin{abstract}
This paper intends to study some of the articles written by Hipólito José da Costa (1774-1823) and published in Correio Braziliense between 1808 and 1823. The chosen period aims at a relationship between the conception of nation and the economic ideas of Hipólito da Costa. Mobilizing his various experiences, such as the trip to Philadelphia in 1798, imprisonment by the Portuguese Inquisition between 1804 and 1805 , and formation at the University of Coimbra between 1795 and 1797, Hipólito da Costa founded the Correio Braziliense in 1808. The newspaper, which circulated between 1808 and 1823, accompanied the main moments of the foreign policy of the Portuguese-Brazilian empire, from the arrival of the Portuguese Crown until the Independence of Brazil. In 1820, with the Porto Revolution and the proposal of recolonization of Brazil, Hipólito began to defend a project of nation for Brazil, object of discussion of this work.
\end{abstract}

Keywords: Correio Braziliense, nation, economic ideas. 
Este artigo pretende discutir o ideário econômico de Hipólito José da Costa veiculado pelo Correio Braziliense, jornal escrito em português e publicado em Londres entre 1808 e 1822. Preferimos o termo ideário à teoria econômica em razão do caráter pragmático de tais ideias, coerente com as linhas mais gerais de reforma da economia do império português em finais do século XVIII e início do século XIX.

Três são os movimentos que moldaram as ideias econômicas apresentadas no Correio Braziliense. Em primeiro lugar, elas foram marcadas pela sua relação com a Ilustração portuguesa e a concepção de império por esta criada. D. Rodrigo de Souza Coutinho, um dos expoentes dessa Ilustração e ocupante de diversos cargos públicos em finais do século XVIII e começo do século XIX, enviou Hipólito da Costa aos Estados Unidos em 1798 com o objetivo de fazer alguns estudos que pudessem ser úteis ao desenvolvimento das artes, da agricultura e do comércio no mundo luso-brasileiro. Dos Estados Unidos, Hipólito José da Costa trouxe três principais contribuições: a relação entre a organização do trabalho e da terra na produção agrícola americana; o protecionismo alfandegário, que teria também impressionado Friedrich List em seu exílio; a liberdade de imprensa.

Em segundo lugar, é necessário entender as ideias econômicas de Hipólito da Costa em sua relação com a maçonaria. Nos Estados Unidos, entrou em contato pela primeira vez com a sociedade secreta. Em sua viagem à Inglaterra, a pedido de D. Rodrigo em 1802 com o propósito de adquirir material régio, Hipólito estreitou laços com as lojas europeias. Em nossa opinião, existe uma relação entre o processo de secularização característico do Antigo Regime e a maçonaria, o que não exclui as suas relações com o liberalismo econômico, a despeito das possíveis contradições. As formas de organização social propostas pela maçonaria foram um meio termo entre as hierarquias medievais estruturadas em torno de uma dada aristocracia e as hierarquias do mundo capitalista contemporâneo, baseadas na meritocracia.

Um terceiro e último ponto que pretendemos abordar neste artigo é a relação entre Hipólito José da Costa e o liberalismo, que assumiu características muito peculiares na obra do autor, dada a maneira pela qual este concebeu o mundo econômico. A grande inspiração teórica do autor foi Jean-Charles Sismondi, no que se contrapôs a José da Silva Lisboa e ao próprio D. Rodrigo de Souza Coutinho, que tiveram como principal inspiração Adam Smith. ${ }^{1}$ Do ponto de vista da política econômica, Hipólito José da Costa

\footnotetext{
${ }^{1}$ Com referência às influências de Adam Smith sobre a obra de Silva Lisboa, vide COUTINHO (2016).
} 
sentiu-se pouco atraído pelo livre-comércio britânico e mais pelo protecionismo industrializante norte-americano. Por fim, no que se refere às concepções de mundo e sociedade liberais, a sociedade proposta pela Revolução Francesa foi completamente abominada. Preferiu-se a isso uma sociedade imaginada pela maçonaria, com uma aristocracia que assumisse a responsabilidade em conduzir a transformação social.

\section{Formação e viagens}

Hipólito José da Costa Pereira Furtado de Mendonça nasceu na colônia do Sacramento em 1774, ainda num período em que a região pertencia ao império português. Esse fato seria fundamental para a formação do autor até mesmo na escolha no nome para o jornal que começou a circular em 1808, chamado de "brasiliense". Enquanto os demais periódicos desse contexto assumiam uma ascendência portuguesa ou luso-brasileira, Hipólito concebia o periódico de sua responsabilidade como "brasiliense". Segundo Carlos Rizzini, um dos biógrafos de Hipólito, o autor seria o idealizador de uma nova concepção de nação ao dizer que "nenhum país" lhe agradava "mais do que o Rio Grande" (RIZZINI, 1957: 46).

O intelectual teve uma formação ampla e rica. Além das viagens, que lhe conferiram um caráter sui generis ao pensamento, os estudos também foram variados. Em 1793, Hipólito começou os estudos de Matemática na Universidade de Coimbra. Depois, cursou Filosofia e, em 1794, optou pelo Direito, bacharelando-se em Leis em 1797. Esta era uma típica formação de um sujeito oriundo da aristocracia luso-brasileira desde a reforma do ensino universitário português, realizada por Pombal em 1772. A formação em Leis incluía estudos de Matemática e Geometria; Filosofia; Latim e Retórica; Ciências Naturais (CALMON, 1974).

Bacharel em Leis, Hipólito José da Costa seguiu para os Estados Unidos em 1798, onde D. Rodrigo o nomeara encarregado de Negócios de Portugal. A missão, qualificada como "científica", deveria trazer para o Brasil, os segredos da agricultura e mineração modernas. O Diário de minha viagem à Filadélfia, produto dessa viagem aos Estados Unidos, expressa, segundo Paulo Roberto de Almeida, muito mais do que "uma simples coleção de observações naturalistas e agrícolas" (ALMEIDA, 2003: 326). Nessa obra, Hipólito se preocupou em elencar diversos aspectos da sociedade e da economia norteamericanas, entendendo suas especificidades como expressões de liberdade. Esta se 
encontrava na religião, na imprensa e nas formas de cultivo agrícola, principalmente o da produção de alimentos, onde já se assistia ao uso da maquinaria e da mão-de-obra livre. ${ }^{2}$ A utilização do dinheiro e a circulação da moeda também configuravam, para Hipólito, uma expressão muito típica da sociedade norte-americana, que demonstrava um gosto acentuado pela especulação.

As expedições a outros países eram parte de um projeto de império arquitetado pelos ilustrados portugueses (MAXWELL, 1998). Tal projeto incluía também a adoção dos princípios de livre-comércio nas relações entre metrópole e colônia.

Foi nos Estados Unidos que Hipólito da Costa travou o seu primeiro contato com a maçonaria, sobre cujas influências temos de nos debruçar se quisermos entender com profundidade o caráter liberal do pensamento do autor e mesmo sua concepção de nação (MUNARO, 2013).

Esse contato com a maçonaria foi reforçado em viagem à Inglaterra em 1802. Não se sabe se D. Rodrigo o enviou para "adquirir livros, máquinas e outros materiais para a Imprensa Régia”, como diz Mecenas Dourado, (DOURADO, 1957: 82) ou se Hipólito já teria viajado com a intenção de travar contato com as sociedades maçônicas, como diz Carlos Rizzini (RIZZINI, 1957: 7). Com o consentimento de D. Rodrigo, Hipólito teria fundado o Grande Oriente Lusitano, a primeira loja maçônica portuguesa. Este também seria o motivo de sua prisão pela Inquisição Portuguesa neste mesmo ano. De acordo com Alberto Dines, os documentos relativos ao processo de Hipólito José da Costa desapareceram. Acredita-se que ele tenha levado os documentos consigo no momento da sua fuga do cárcere inquisitorial em 1805: "Tudo sugere que o documento tenha sido furtado pelo fugitivo e por dois motivos: para eliminar as provas que o incriminavam (assim como os demais companheiros da Maçonaria lusa) e para armar-se de provas quando iniciasse a cruzada contra o Santo Ofício" (DINES, 2002: 457). ${ }^{3}$

Em 1805, Hipólito da Costa fugiu da prisão e foi para a Inglaterra, passando a residir em Londres. Segundo Mecenas Dourado, o surgimento do Correio "foi um

\footnotetext{
2 “São muitas no Diário, as suas cautelosas referências ao que ia descobrindo e observando em Filadélfia e Nova Iorque. Não consignou, em documento destinado ao governo de Lisboa, a mais leve admiração pelos costumes políticos da América. Mas a prática desses costumes numa nação de poderes fundados no voto popular, de imprensa livre, de eleições livres, de livre crença, de livres debates, há de ter-lhe causado profunda impressão. Do entusiasmo pela democracia diz bem o fato, de suma importância em seu futuro, de ter-se feito maçom em uma loja de Filadélfia" (RIZZINI, 1957: 6).

${ }^{3}$ Em Narrativa da Perseguição, Hipólito da Costa diz: "É desgraçada a situação do homem que se vê obrigado a falar de si mesmo e fazer sua própria apologia: mas que remédio quando me vejo atacado e infamado sem se me conceder recurso?" (COSTA, 1981 [1811]: 6-7).
} 
fenômeno napoleônico" (DOURADO, 1957, t. 2: 580) e não teria acontecido não fosse a invasão de Portugal pelos franceses e a fuga de Hipólito dos cárceres da Inquisição. O principal jornal de oposição à política de Estado português circulou entre 1808 e 1822, ou seja, da transferência da Coroa Portuguesa até o final da vida de Hipólito José da Costa, que morreu em 1823.

\section{Hipólito da Costa e O Correio Brasiliense}

Em 1808, foi fundado em Londres o Correio Braziliense. Tendo sido o ano também da transferência da corte para o Brasil, o início da circulação do jornal coincidiu com uma profunda crítica à forma como o império luso-brasileiro se organizou a partir de sua sede no Rio de Janeiro.

Para entendermos o caráter das ideias econômicas veiculadas pelo Correio são fundamentais duas observações preliminares.

A primeira observação é a da relação entre a circulação dos jornais enciclopédicos ${ }^{4}$ e os novos grupos sociais surgidos da crise do antigo regime português, em particular um grupo de comerciantes mais ligados aos interesses do comércio atlântico do que aos da metrópole portuguesa. Os comerciantes, que circulavam por Londres, Lisboa e pela corte do Rio de Janeiro, não somente eram leitores do periódico, como também seus financiadores:

(...) sendo seguro que o jornal não poderia viver muito tempo sem apoios, parece certo que os suportes teriam vindo dos comerciantes portugueses, numa fase, e noutra fase do governo, de comerciantes ingleses, embora os interesses entre os primeiros e os segundos não fossem coincidentes (TENGARRINHA, 2002: 243).

\footnotetext{
${ }^{4} \mathrm{O}$ Correio não era à época, concebido como gazeta, como seria chamado depois. O mais correto, como observa José Tengarrinha, é a denominação de jornal enciclopédico, que teria caráter mais informativo, tanto em termos científicos, quanto políticos, do que de propaganda política, que seria uma função mais adequada para a gazeta: “(...) são jornais de conhecimento genérico que podemos designar 'enciclopédicos'. (...) embora sem o título de 'enciclopédicos', muitos outros periódicos tiveram, na verdade, a mesma natureza, propondo-se divulgar conhecimentos científicos, literários, filosóficos, artísticos para um público mais amplo do que de hábito (...) Transmitiam uma mensagem social e politicamente progressiva, baseando o motor do progresso humano no próprio homem, na sua capacidade de conhecer, de racionalizar, de dominar a natureza, sob inspiração do ideário iluminista" (TENGARRINHA, 2002: 224-225).
} 
Outro novo grupo que emergia neste momento, o dos intelectuais ilustrados, propunha uma profunda reforma nas linhas gerais da organização política imperial. Utilizando os instrumentos do livre câmbio e livre comércio, os "estrangeirados" 5 arquitetavam um projeto de império que mantinha, em linhas essenciais, o exclusivo metropolitano e alguns monopólios, mas que se abria para o livre comércio com outros impérios, como o britânico. Também se iniciava uma discussão sobre o papel da industrialização na sociedade portuguesa e da maquinaria na agricultura e na mineração. Esse grupo, cujo pensamento econômico encontra-se compilado em coleção organizada pelo Banco de Portugal, acreditava também que reformas fiscais e monetárias seriam cruciais para a estabilidade e grandeza do império português. Os pensadores foram também intitulados por Kenneth Maxwell como “a geração de 1790” (MAXWELL, 1998), e ocupariam cargos públicos de fundamental importância durante os reinados de D. José I, D. Maria I e D. João VI.

Nesse sentido, já no primeiro número do Correio Braziliense, Hipólito da Costa referia-se ao Brasil como nação e também como império. No próximo tópico deste artigo, aventamos algumas hipóteses sobre os termos nação e império em Hipólito José da Costa, mas, desde já, reforçamos o alinhamento do autor com a geração de 1790, que entendia a nação como um Estado independente, que se afirmava pelos seus potenciais econômicos, e o império, uma unidade territorial, que congregava diversas regiões e tinha uma expressão planetária:

\footnotetext{
5 "Todos eles compunham uma geração de estrangeirados; tanto porque viviam fora de Portugal quanto porque observavam a situação portuguesa com base em tal deslocamento do olhar (ANDRADE, 1980; MONCADA, 1941). A ambiguidade profícua dessa situação de estrangeirado adviria da observação da realidade estrangeira por parte de alguém que tem no seu país de origem a referência. A comparação com outros países parecerá, nesse caso, irresistível e inevitável. Os estrangeirados portugueses do século XVIII preocupavam-se com o atraso cultural do país. Consideravam que a situação do seu Portugal contemporâneo era de decadência: perante os países mais avançados da Europa; à luz dos rumos tomados pela colonização; diante do poder que um dia o país acreditou possuir" (BOTO, 2010). É provável que uma primeira expressão do termo tenha sido cunhada por Jaime Cortesão (CORTESÃO, 1956, vol. 2: 99106) No Dicionário da História de Portugal, o termo ficou sob o encargo de Antonio Coimbra Martins (MARTINS, 1965: 122-129). Para uma revisão do conceito, vide MACEDO (1974); FALCON (1995) e CARNEIRO, DIOGO e SIMÕES (2000). Sobre os "estrangeirados" e Hipólito da Costa, vide Alberto Dines: "graças à circunstância de estarem no exterior, os estrangeirados constituem outra das afortunadas casualidades portuguesas. Rebeldes, marginais ou visionários, conseguiram pontuar a história das ideias com impulsos modernizadores que, no conjunto e devidamente perspectivados, constituem um esforço consistente, ainda que intermitente, e ao qual não faltam grandes doses de coragem (...) Ignora-se quem os alcunhou - com sutil intenção malévola - de estrangeirados, mas sabe-se que Jaime Cortesão apodou o grupo adversário como "castiços". Com a mesma ironia, estes poderiam ser chamados de nativistas, tradicionalistas ou conservadores. Por oposição, os estrangeirados são os cosmopolitas e reformadores" (DINES, 2000: 443-444).
} 
Sendo também nós aquela nação, que comprou a sua liberdade e independência com estes jornais políticos, seremos agora a única que se há de achar sem estes socorros, necessários a um estado independente o qual poderá algum dia rivalizar, pela sua situação local, em que a natureza pôs o vasto Império do Brasil às primeiras potências do mundo (Correio Braziliense, vol. 1, jul 1808: 4)

Nesta mesma edição do Correio Braziliense, o autor iniciava a seção Miscelânea com "pensamentos vagos sobre o império do Brasil". Projetando uma nova sede para o império luso-brasileiro, Hipólito acrescentava que:

Umas das causas principais do mau governo do Brasil era o desleixamento, quase irremediável, da corte de Lisboa, a respeito daquela importante colônia, o que era ocasionado pela atenção, que era necessário prestar às relações estrangeiras, com o que se esquecia naturalmente a administração de um território, que por mais interessante que fosse, sempre se reputava secundário, em consequência da magnitude dos outros objetos que concorriam com ele (Correio Braziliense, vol. 1, jul. 1808: 63-64).

A segunda observação a se fazer, antes de encetarmos propriamente a discussão das ideias econômicas do Correio Braziliense, é quanto ao papel que o Correio Braziliense exerceu naquele contexto. O jornal circulava por todo o império português, visando principalmente à informação da política. Embora dividido em seções, Política, Artes e Comércio, Literatura e Ciências, Miscelânea, o Correio Braziliense tratava, essencialmente de política. Na parte relativa à literatura não raro eram analisadas obras de economia política. Embora compradas pelo público letrado, os jornais eram, muitas vezes, lidos em praças públicas e entre membros de sociedades secretas, como a maçonaria. A circulação dos periódicos nos porões dos navios, nos baús dos caixeirosviajantes, promovia uma rápida e difusa circulação de ideias. A leitura dos jornais tornava-se um costume cotidiano das pessoas, anunciando as mudanças que marcavam o período. Em sua viagem aos Estados Unidos, num dia sem circulação do periódico lido por Hipólito, este observou: "Hoje, sendo o dia em que o Presidente mandou jejuar pela sua proclamação, todas as obras pararam, e foi guardado como dia santo. Não houve gazeta" (Hipólito da Costa, 2004 [1798]: 89). Esta era a importância do periódico na vida de letrados. 
Em Portugal, esse tipo de circulação ganhou campo com a 1ª invasão napoleônica, em 1807, com o objetivo de criar uma resistência aos franceses. Abriu-se, assim, uma brecha na censura inquisitorial advinda com a Viradeira de Maria I. Contudo, após a expulsão das tropas napoleônicas de Portugal em 1808 e com a ocupação inglesa, a proibição da circulação de impressos no império português voltou a acontecer. Da mesma maneira como as gazetas haviam se tornado instrumento de crítica aos franceses, elas se tornaram, com a transferência da corte para o Brasil, libelo contra a política de governo dos Bragança na América. A política de livre-comércio negociada com a Inglaterra não avançava para uma superação dos entraves estruturais do reino. Na visão de Hipólito da Costa, as medidas, ao contrário, prejudicavam enormemente o comércio luso-brasileiro e o erário régio.

Em 1808, mesmo ano da transferência da corte de Portugal para o Brasil, iniciouse a circulação do Correio Braziliense em Londres. Financiado por comerciantes lusobrasileiros, o Correio passou a ter a antipatia imediata da Coroa. Periódicos antagonistas foram, então, lançados em Londres, Paris, Hamburgo e Lisboa. O objetivo era o combate às ideias do Correio Braziliense. Seus principais opositores foram: "O Investigador Portuguez em Inglaterra", ${ }_{6}^{6}$ publicado em Londres entre 1811 e 1819, talvez o principal oponente de Hipólito José da Costa e do Correio Braziliense, e "O Observador Lusitano em Pariz" ou "Collecção Literária, Política e Comercial”, publicado em Paris em 1815. ${ }^{7}$

$\mathrm{Na}$ medida em que as estruturas sociais do império luso-brasileiro iam se modificando e surgiam novas tensões, em particular em decorrência da crescente influência dos comerciantes que atuavam entre Brasil e Inglaterra, Hipólito da Costa também assumia novos posicionamentos. A abertura dos Portos em 1808 e os Tratados de 1810 levaram Hipólito a refletir a fundo sobre as consequências do livre-comércio para o império luso-brasileiro, um tema caro para o Correio Braziliense. A seguir, as pressões

\footnotetext{
${ }^{6}$ Foram redatores do referido periódico os médicos Bernardo José de Abrantes e Castro, Vicente Pedro Nolasco da Cunha e Miguel Caetano de Castro e, a partir de janeiro de 1814, José Liberato Freire de Carvalho (TENGARRINHA, “O Jornalismo...”, in Correio Braziliense, vol. 30, 2008: 223).

${ }^{7} \mathrm{~A}$ circulação de periódicos em resposta ao Correio é profusa. Argus Lusitano ou Cartas Analíticas, Londres (1809), em 4 edições; O Espelho Político e Moral, Londres (1813-1814); Microscópio de Verdades ou Óculo Singular, Londres (1814), em 7 edições; O Portuguez ou Mercúrio Político, Londres (18141821), em 12 volumes; O Espectador Português, Londres (1816-1817), em 2 volumes; Anais das Ciências, das Artes e das Letras, Paris (1818); Le Plenipotentiaire de la Raison, Hamburgo (1818); O Campeão Portuguez ou O Amigo do Rei e do Povo, Londres (1820-1821), em 4 volumes; O Padre Amaro ou Sovela Política, Histórica e Literária, Londres (1820); Azorrague das Cortes Novas, Londres (1820); O Contemporâneo Político e Literário, Paris (1820); Folhetos portugueses contra o Correio (MOREL, 2002), Correio Braziliense, vol. 30, 2008: 310-311).
} 
para a abolição da escravatura nas colônias inglesas induziu Hipólito a romper o silêncio sobre a possibilidade do fim da escravidão no império português. ${ }^{8}$ Finalmente, em 1820 , com a proposta de recolonização do Brasil, trazida à tona pela Revolução do Porto, Hipólito passou a defender mais ativamente a independência da colônia e a formação de um novo Estado, ao mesmo tempo em que propunha a proteção alfandegária e o desenvolvimento das manufaturas no Brasil. Livre comércio, fim da escravidão e independência do Brasil tornavam-se, então, alguns dos temas fortes do Correio Braziliense aos quais passamos à análise neste momento.

Alguns dos temas tratados no Correio Braziliense nortearam toda a sua circulação e, de certa maneira, sintetizam as ideias econômicas de Hipólito da Costa. Conforme dito acima, o autor não pretendia fazer uma economia política no sentido de teorizar sobre o funcionamento do mercado. Sua preferência residia claramente sobre as práticas econômicas e sobre a política econômica mais adequada ao império luso-brasileiro.

Um primeiro tema que sintetiza a maneira como Hipólito da Costa expunha suas ideias é o tema dos Tratados de Comércio de 1810. Embora fosse favorável ao princípio geral dos Tratados, que era o de uma organização do império luso-brasileiro com base nos princípios de livre-comércio, Hipólito da Costa se mostrou completamente contrário à maneira como D. Rodrigo de Souza Coutinho e Lord Strangford deram forma aos Tratados. Para ele, as cláusulas tornavam Portugal um refém do comércio inglês e rifavam a principal colônia portuguesa, o Brasil (Portugal, antes da abertura dos portos, era o principal porto de reexportação dos produtos brasileiros para a Europa) (ALEXANDRE, 1993). No caso do Brasil, a empresa era "uma das mais delicadas", uma vez que "o negociador brasiliense" não teria precedentes que o guiassem, o que não era, certamente, o caso de Portugal, que já tinha um longo histórico de comércio com a Inglaterra, baseado em pautas de produtos bastante tradicionais, como o vinho e o azeite (Correio Brasiliense, vol. 2, jan. de 1809: 129-130). À inexperiência mercantil como Estado independente, Hipólito acrescentava novos riscos à colônia: “(...) os produtos principais do Brasil estão longe de terem grande consumo na Inglaterra, que são nela proibidos por causa da competência em que se acham com as colônias britânicas" (Correio Brasiliense, vol. 2, jan. de 1809, p. 130).

\footnotetext{
${ }^{8} \mathrm{O}$ processo de abolição da escravatura no império britânico também foi gradual, como o brasileiro. Em 1807, decretou-se o fim do tráfico para as colônias com o Slave Trade Act. No entanto, a abolição da escravatura viria somente em 1833, com um novo Ato, o Slavery Abolition Act.
} 
Um segundo tema a partir do qual podemos pensar as ideias econômicas expostas no Correio Braziliense é o tema da escravidão. Um dos pontos que mais chama a atenção é o silêncio sobre o tema, quando havia já uma enorme pressão internacional para a abolição do tráfico e da escravidão. Esse silêncio foi ressaltado por poucos autores do período: por Ribeiro Sanches, pensador português formado doutor em medicina pela Escola de Salamanca em 1724, por Antônio Ribeiro dos Santos (NEVES, 2001) e, finalmente, por Hipólito José da Costa. Influenciado pela viagem à Filadélfia em 1798, onde já se faziam as primeiras experiências de substituição do trabalho escravo pelo trabalho imigrante e pelo maquinário agrícola, Hipólito da Costa desafiou definitivamente a quebra de silêncio sobre o pilar fulcral do império português, a escravidão, na ocasião da criminalização do tráfico pelo Parlamento inglês em 1811:

Há, porém, um ponto, sobre que mais de uma vez temos falado, em nosso periódico, dando nisso nossa decidida opinião, e a respeito do qual observamos, que todos os escritores do Brasil guardam ainda silêncio; e é este ponto, a gradual e prudente extinção da escravatura (Correio Braziliense, vol. 29, jul 1822: 574).

1811 foi também o ano em que Hipólito José da Costa rompeu em definitivo com seu antigo tutor, D. Rodrigo de Souza Coutinho, passando a gravitar em torno do duque de Sussex, sexto filho de Jorge III e irmão de Jorge IV. A proximidade com o duque reforçou a defesa da abolição da escravatura no Império Português. ${ }^{9}$ É digno de nota que este também foi o ano da publicação da Narrativa da perseguição, obra em que Hipólito da Costa descreveu os anos passados nos cárceres da Inquisição. A intolerância foi o tema que perpassou as posições tomadas contra a escravidão e contra a Inquisição.

\footnotetext{
${ }^{9}$ Augustus Frederik (1773-1843), sexto filho de Jorge III, irmão de Jorge IV e grão-mestre da Grande Loja da Inglaterra desde 1811, defendia o fim do tráfico de escravos, a concessão de direitos civis aos judeus e aos que não professavam a religião anglicana e promoveu reformas parlamentares - pontos igualmente defendidos por Hipólito da Costa. Desenvolveu-se forte amizade entre Augustes Frederik, o duque de Sussex, e Hipólito da Costa, que já haviam se conhecido em 1802, quando da primeira viagem de Hipólito a Londres. "As relações de Hipólito com Augustes Frederik (...) proviriam, sem dúvida, das suas diligências para obter da Grande Loja da Inglaterra o 'warrant of constitution' impetrado pelas incipientes lojas portuguesas. Com o tempo apertaram-se as relações, convertendo-se, no curso de vinte anos, em rara e estreita amizade. Foi Sussex padrinho de casamento de Hipólito e padrinho do seu filho varão, também chamado Augusto Frederico" (RIZZINI, 1957: 17). Isabel Lustosa discorre de maneira detalhada sobre as relações entre Hipólito da Costa e o duque de Sussex em seu texto "His Royal Highness e Mr. da Costa". In Correio Brasiliense, vol. 30, 2008: 15-60. É uma revisão atual da literatura sobre o tema.
} 
O terceiro tema importante para a compreensão das ideias econômicas de Hipólito é o tema da independência do Brasil. O tema, que apareceu com clareza nos artigos do autor desde a Revolução do Porto de 1820, compreendia a nação como um território econômico, no qual se delineavam as trocas e cujas fronteiras coincidiam, teoricamente, com as do mercado como instituição econômica e política (ROSANVALLON, 2002). A ambiguidade, no entanto, residia na ideia de nação como um prolongamento do império e não como uma ruptura com este (PEREIRA, 2013). Para Hipólito da Costa, o desenvolvimento do comércio e da manufatura, pressupostos do progresso da nação em Adam Smith, dependiam, no império português, da relação ressignificada entre Portugal e suas colônias (CARDOSO, 2001). Esta concepção nacional/imperial foi uma concepção da crise do Antigo Regime Português que se fixou nas primeiras imagens sobre o Império do Brasil. A grandeza e a extensão dos territórios eram as pedras fulcrais do desenvolvimento da riqueza do reino, identificado, pelos ilustrados portugueses, com a nação portuguesa:

No "Correio Brasiliense" bateu-se pela "grandeza", não pela "divisão" do Brasil. Enquanto essa noção de "integridade" se conciliou com a de "continuação" — mas coroada por seu destino imperial — propugnou a união luso-brasileira. Estaria de acordo com as tendências maçónicas se advogasse, em 1817, a revolução pernambucana, encabeçada por seu parceiro de ideal Domingos José Martins (CALMON, 1974: sn).

Para que a nação passasse a existir no Brasil, seriam necessários alguns elementos. Um primeiro deles, base da nação do século XIX, era a língua. Ao difundir o Correio Braziliense, o autor pretendia também contribuir para a consolidação da língua portuguesa no império luso-brasileiro:

Feliz eu, se posso transmitir a uma nação longínqua e sossegada, na língua que lhe é mais natural e conhecida, os acontecimentos desta parte do mundo, que a confusa ambição dos homens vai levando ao estado da mais perfeita barbaridade. O meu único desejo será de acertar na geral opinião de todos, e para o que dedico a esta empresa todas as minhas forças, na persuasão de que o fruto do meu trabalho tocará a meta da esperança a que eu me propus (Correio Braziliense, vol. 1, jul 1808: 4). 
A obsessão pela língua nacional vinha de longa data, desde que Hipólito publicara uma Gramática da Língua Portuguesa. Coadunava-se com este projeto de unificação do idioma sua proposta de liberdade de imprensa. Ambos apontavam para a necessidade de reforma do império português, que apresentava elementos anacrônicos em relação aos preceitos de liberdade do mundo que se iniciava com Revolução Americana e a Francesa. Também eram elementos obsoletos a Inquisição e a intolerância religiosa; a escravidão e os monopólios ofensivos à liberdade de comércio; e, por fim, a censura à imprensa. $\mathrm{O}$ Correio Braziliense era um instrumento poderoso de crítica a esses três esteios, ao mesmo tempo em que encerrava uma construção muito particular do liberalismo econômico.

Juntamente com a língua, a defesa da existência da nação no Brasil ${ }^{10}$ era acompanhada de um projeto de interiorização da capital, sugerida em artigos do Correio Braziliense:

Os brasileiros nos permitirão lembrar-lhe, ao mesmo tempo que louvamos estes seus esforços para o melhoramento do Brasil; que eles conservam obstáculos à sua prosperidade, que retardarão infinitamente os progressos da civilização e da agricultura e comércio interno. E, por ora, faremos menção de dois. Um é a má escolha da sede do governo; outro, a falta de população própria e conveniente ao estado atual do Brasil (Correio Braziliense, vol. 10, março de 1813: 373-377).

A ideia era a da criação de maior unidade, tanto cultural, quanto territorial. Para esta também contribuiriam as tarifas alfandegárias e o desenvolvimento das manufaturas no Brasil. Segundo Hobsbawm, a concepção de um grande território, unido por um conjunto de tarifas alfandegárias comuns, artes desenvolvidas, dentro das quais se enquadravam as manufaturas, e uma língua comum, foi o elemento delineador da moderna ideia de nação no século XIX. ${ }^{11}$

\footnotetext{
${ }^{10}$ Conforme dito acima a "nação" era entendida como um espaço econômico e a existência de duas nações, a brasileira e a portuguesa, não violava a existência de um império português, que seria a unidade política. Aliás, é nesse ponto que residia o projeto de um Reino Unido entre Portugal e Brasil, ambos independentes, mas constituindo um único e poderoso império. D. Rodrigo teria sido um dos primeiros que, dentro da geração de 1790, defenderam este projeto com a consequente transferência da sede da corte portuguesa para o Brasil. Hipólito da Costa avançou nessa ideia, pensando o desenvolvimento das manufaturas a partir da interiorização da capital na colônia.

11 "A característica básica da nação moderna e de tudo o que a ela está a ligado é a sua modernidade". HOBSBAWM, 1990: 27).
} 


\section{Ideias e ideologia econômicas em Hipólito da Costa}

Os temas atrelados à economia que levantamos na parte anterior servem-nos de guias para tratar da especificidade do liberalismo em Hipólito José da Costa. Ferrenho defensor das liberdades - de imprensa, de força de trabalho e de religião, Hipólito da Costa não seguiu os preceitos de Adam Smith, como teria feito D. Rodrigo de Souza Coutinho (CARDOSO: 2001). O autor foi inspirado mais pela economia política de Sismondi, cuja obra Hipólito traduziu e publicou nos últimos volumes do Correio Braziliense, do que pela do filósofo escocês. ${ }^{12}$ No entanto, alguns grandes precursores de Adam Smith, como Helvetius, foram citados em algumas passagens do Correio Braziliense. A intenção era a de se chamar a atenção para a impossibilidade de constituição de uma sociedade de homens educados, sem que a escravidão, o fundamento de toda a desigualdade no império luso-brasileiro, fosse eliminada:

A maior parte de nossos sentimentos e de nossas ações depende dos acidentes de nossa educação; e um homem educado com escravos, não pode deixar de olhar para o despotismo como uma ordem de coisas natural. Ulteriores ocorrências na vida, que são (como diz Helvécio) ainda traços na educação do homem, pode fazer mudar em alguns indivíduos essa errada preocupação; mas a maioridade dos homens, que são educados com escravos, deve ser inclinada à escravidão, e quem se habitua a olhar para seu inferior como escravo, acostuma-se também a ter um superior que o trate como escravo (Correio Braziliense, vol. 29, jul 1822: 574-575).

Antes de ter contato com Sismondi, Hipólito da Costa havia traduzido obras que também influenciaram esta sua forma de conceber o mundo econômico, conferindo contornos muito específicos e ambíguos ao seu liberalismo. Provavelmente sob a sugestão do Conde de Linhares, D. Rodrigo de Souza Coutinho, Hipólito verteu para o português a História do Banco da Inglaterra, de E. F. Thomas Fortune, e os Ensaios econômicos e filosóficos de Benjamin Rumford (DOURADO, 1956: 80-81).

Sob a influência dessa gama de autores, o mercado, em Hipólito da Costa, não era uma entidade abstrata que regia o funcionamento da sociedade como um todo. Esta

\footnotetext{
12 "Hipólito transcreveria, no Correio Braziliense, a partir de 1816 (CB, 16: 338), a tradução em português dos Princípios de economia política aplicados à legislação do commercio, obra recente de Sismondi correspondendo à sua fase liberal” (ALMEIDA, “O nascimento do pensamento...”, 2008: 328).
} 
continuava a ser governada pela política, embora uma política sem os abusos do Estado absolutista, como a censura à imprensa e a Inquisição. De acordo com Marcos Morel, a concepção hobbesiana de demarcação entre a esfera privada, domínio da livre consciência individual, e a esfera pública coletiva, domínio do poder do Estado, foi um aspecto do pensamento de Hipólito da Costa, como de toda a maçonaria. A influência desta é um aspecto fundamental para compreender os contornos e ambiguidades das ideias econômicas de Hipólito da Costa. ${ }^{13}$

Nesse sentido, o movimento maçônico em geral, e o dos países ibéricos em particular, fez parte do processo de secularização característico de finais do século XVIII e primórdios do século XIX (BARATA, 2006; DIAS \& DIAS, 1980; MARQUES, 19901997). Embora calcada em forte senso aristocrático, sendo organizada segundo hierarquias inspiradas nas corporações de ofício, a maçonaria também foi uma instituição pela qual se pensaram as novas liberdades e as ideias características de um mundo livre. Como maçom, Hipólito da Costa combatia dois extremos: o jacobinismo revolucionário e o absolutismo tradicionalista: "Percebe-se em Hipólito da Costa uma dupla posição diante das maçonarias: de um lado concebia estas como embriões de uma sociedade moderna e liberal e, de outro, fazia um vínculo entre tais agremiações e um acentuado sentimento aristocrático" (MOREL, 2008: 292). ${ }^{14}$

É de se notar que o liberalismo de Hipólito da Costa se caracterizou por uma série de ambiguidades, em razão da combinação entre as ideias modernizantes e as estruturas do império português. A primeira ambiguidade é que, ao mesmo tempo em que se denunciavam os monopólios de antigo regime, resguardavam-se alguns privilégios da classe mercantil luso-brasileira diante do poderoso império britânico. A defesa do livrecomércio não era absoluta. Hipólito percebeu que os diferentes países circunscreviam-se a situações muito distintas e as políticas de livre-comércio podiam não ser válidas para

\footnotetext{
13 "Na medida em que o domínio do político seria monopólio do Estado, os indivíduos poderiam ter as suas convicções, mas somente nos limites privados, isto é, não políticos. E mesmo que a maior parte das maçonarias tenha desempenhado um papel político importante, tal concepção sintonizava-se com o poder centralizador da Monarquia absolutista portuguesa, sobretudo na sua vertente ilustrada e luso-brasileira (...) Tal posição que chamamos de hobbesiana expressava-se quando seus correligionários apresentavam-se como guardiões dos altos valores maçônicos: beneficência, filantropia, sabedoria, justiça, uso equilibrado da razão" (MOREL, 2008: 285).

14 “As maçonarias (...) assumem publicamente o papel de espalhar as Luzes pelos lugares sombrios da sociedade, adquirindo grande prestígio social e se tornando meios privilegiados de escoamento de informações políticas. Elas serviram de espaço de intercâmbio para os princípios filosóficos tanto durante a Revolução Francesa, quanto durante a Independência Brasileira, quando a força dos governos era incapaz de lidar com a rápida difusão de noções relativas à liberdade de expressão”. (MUNARO, 2013: 61).
} 
todos. Além disso, Hipólito apontou para a dependência clara da Inglaterra em relação a suas colônias, mostrando, no mínimo, uma opinião corajosa em um contexto em que a política externa inglesa era a dominante em termos internacionais:

A extensão do comércio britânico abrange as quatro partes do mundo, e não obstante os grandes lucros, que a Inglaterra tira do negócio com o continente da Europa, o comércio com as outras partes ainda o excede muito (...) o comércio inglês com a América, África e Ásia é muito maior que o comércio inglês com a Europa (Correio Braziliense, vol. 1, jul 1808: 41).

Assim como em Adam Smith, as manufaturas e as artes eram os elementos centrais do desenvolvimento das nações, não o comércio. No entanto, as inspirações de Hipólito podem ter sido outras, que não A riqueza das nações. Além de autores diversos da economia política, foi da experiência na Filadélfia, que Hipólito retirou sua principal inspiração para a defesa de uma política tarifária protecionista e da industrialização. Alguns o aproximariam de Friedrich List por esse motivo (que também esteve nos Estados Unidos e foi influenciado pelas ideias de Alexander Hamilton). De certa maneira, essa experiência concreta do protecionismo e da industrialização conferiu um matiz um tanto diferente às ideias econômicas de Hipólito da Costa e às dos demais autores da geração de 1790, à qual também pertenceu. Com o Correio Braziliense, poderíamos dizer que Hipólito assinou a ruptura de suas ideias econômicas com as ideias de sua geração, tornando-se um sujeito extremamente original, inclusive no que se refere à concepção de império luso-brasileiro. No entanto, o tom que adotou contra os republicanos venezuelanos do Correio del Orinoco $^{15}$ demonstra sua posição ainda conservadora em relação aos processos revolucionários. Sua estupefação em relação às revoluções populares, que conduziram às independências no império espanhol, levou-o a dizer que:

\footnotetext{
15 “(...) o Correo del Orinoco, semanário fundado por ordem de Simón Bolívar, era publicado na cidade de Angostura (atual Ciudad Bolívar), onde em 1818 estava a base das forças revolucionárias durante a Guerra pela Independência da Venezuela. Teve 128 números, entre junho de 1818 e março 1822, com mais cinco edições extraordinárias, não numeradas. Contou com 16 colaboradores, o que torna quase impossível a tarefa de identificação dos artigos não assinados e aqueles assinados por pseudônimos. Voz do movimento pela independência política da projetada República da Colômbia, era arma tática de informação, responsável por difundir entre compatriotas e estrangeiros os ideais e propósitos do movimento republicano, assim como disseminar uma ideia positiva dos resultados das suas empreitadas" (FERNANDES, 2009: 145).
} 
Ninguém deseja mais do que nós as reformas úteis, mas ninguém aborrece mais do que nós que essas reformas sejam feitas pelo povo. Reconhecemos as más consequências desse modo de reformar — desejamos as reformas, mas feitas pelo Governo e urgimos que o Governo as deve fazer enquanto é tempo para que se evite serem feitas pelo povo (Correio Braziliense, vol. 6, jan. 1811: 570)

Apesar de romper com algumas ideias econômicas de sua geração, Hipólito da Costa demonstra clara preferência pela forma de governo centralizada, não popular. Era a favor da liberdade individual, da representação nas Cortes, da monarquia constitucional, "mas, alarmado com a inquietação social e com os rumos que tomara a Revolução Francesa, tinha pavor da desordem pública e se opunha a qualquer sistema republicano" (MOLINA, 2015: 98). Criticando a Revolução Pernambucana de 1817, a partir da qual se desenrolou o debate com o Correo del Orinoco, Hipólito atentava para o fato de que aquela poderia culminar na fragmentação do país, arriscando os projetos de unidade e integridade territoriais, cruciais para o desenvolvimento do império como um todo.

Ainda no que concerne a aspectos do pensamento de Hipólito da Costa que propunham mais a preservação de algumas estruturas do que sua transformação radical, citamos o tema da separação entre Brasil e Portugal. Esse tema, colocado dessa maneira, somente surgiu com a Revolução do Porto de 1820. Pensá-lo como um precursor da independência do Brasil é, portanto, equivocado e anacrônico. Hipólito foi um homem da transição de um império a outro, de uma nação a outra, de uma forma de organização econômica a outra. ${ }^{16}$ Antes da posição pela independência do Brasil ou pelo império do Brasil, foi da ideia de império de D. Rodrigo e dos ilustrados da mesma geração que Hipólito da Costa partilhou.

Hipólito sempre defendeu o sistema monárquico e a Casa de Bragança e sempre defendeu a união entre Portugal e Brasil, só aceitando a independência quando ela, a seu ver, já se havia consumado. Oscila entre a defesa da manutenção de um comércio colonial integrado no espaço metrópole-colónia, considerado como "comércio interno", e como tal não devendo ser permitido

\footnotetext{
16 "Hipólito da Costa transitou entre Impérios, palavra que no Dicionário de Antonio Moraes e Silva (seu contemporâneo e também alinhado ao grupo luso-brasileiro) possuía diversos significados. Alguns mais perceptíveis no domínio da objetividade política, como os "direitos de que goza o imperante, ou soberano" ou ainda o "território com os vassalos do soberano"'” (MOREL, 2008: 319).
} 
a nações estrangeiras, e uma proposta de reorganização ponderada das pautas alfandegárias. E em outras passagens, como quando do rescaldo da revolta pernambucana de 1817 , afirma a identidade dos interesses comerciais com a manutenção da união dos dois reinos (PAULA \& LIMA, 2008: 126).

Conforme já apontado acima, reaparece neste excerto a ideia de pensar a nação como um território econômico amplo, baseado na divisão de trabalho entre a metrópole e seus domínios. A divisão de trabalho, devidamente incentivada, resultaria no desenvolvimento do império como um todo: nem só do Reino, nem tão somente da colônia.

A necessidade de se reformar um império de antigo regime, que ia absorvendo as novas influências do pensamento econômico, mas, mantinha suas estruturas políticas, resultou em outra ambiguidade, que foi quanto aos contornos que a economia política adquiriu entre os reformadores do império português. O precursor de tais ideias foi $\mathrm{D}$. Rodrigo de Souza Coutinho, padrinho intelectual e maçom de Hipólito José da Costa. D. Rodrigo repensou o império português a partir das linhas gerais propostas por Adam Smith em A riqueza das nações e alguns dos princípios de livre comércio que não violassem a unidade do império português, mas a reforçassem. ${ }^{17}$

O diálogo entre economia e política na obra de Hipólito da Costa é permanente. A economia não pode ser tratada em separado da política e, por esse motivo, não há como falar em uma teoria econômica propriamente dita. Política e economia complementam-se nas quatro seções que compõem o jornal: Política, Comércio e Artes, Literatura e Ciências e Miscelânea. Por esse motivo, a economia política concebida por Hipólito assumiu menos o caráter teórico, de busca de leis gerais de funcionamento do mercado e da sociedade, do que o caráter de política econômica. O objetivo principal era o da reforma do império luso-brasileiro, tanto no sentido de aproximar Portugal e Brasil, atentando para os riscos de comercializar com a Inglaterra, um país forte e com um imenso império colonial, como também no sentido de, após 1822, prover o Brasil de seus principais meios

\footnotetext{
17 "Em sintonia com o multifacetado ideário iluminista, colocava-se a existência de uma união natural entre as diversas partes do mundo português que, diante das novas relações internacionais (Revolução Francesa e suas possíveis consequências, crescente influência na Inglaterra sobre Portugal), deveria reformular-se de maneira profunda para manter-se unido. Ou seja, d. Rodrigo, numa perspectiva reformista, propunha um novo império atlântico, inspirado nas formulações de Adam Smith sobre as possessões nacionais e também retomando ideias do bispo Azeredo Coutinho, que pregava uma redefinição de papeis que gerasse outro equilíbrio geopolítico no âmbito da nação portuguesa”. (MOREL, 2008: 273).
} 
para atingir o status de nação desenvolvida. É dentro desses limites que devemos entender as ideias econômicas de Hipólito da Costa.

É de se chamar a atenção que, apesar desse caráter mais pragmático da economia política, os intelectuais de começo do século XIX, como Hipólito da Costa, D. Rodrigo de Souza Coutinho e José da Silva Lisboa, entendiam-se a si mesmos como propagadores da ciência econômica. A instituição de uma "cadeira e aula pública" de economia política no Rio de Janeiro foi uma medida tomada pelo príncipe regente em 23 de fevereiro de 1808, logo após a chegada da família real ao Brasil. A despeito disso, D. Rodrigo de Souza Coutinho, o Conde de Linhares, diria que o ensino de economia política no Brasil era difícil e as pessoas não estavam preparadas para recebê-lo, resultando em "maiores absurdidades sobre a economia política" (DOURADO, 1956, t. 1: 270).

Esse caráter pragmático e conservador do liberalismo português deveu-se não somente à sua ligação com a maçonaria, mas também pela forma como as ideias circulavam: "foi a imprensa periódica ou o jornalismo português em Londres quem, por aquele tempo, principiou a difundir abertamente entre nós, por todas as classes da nação, as ideias liberais" (SORIANO apud TENGARRINHA, 2008: 238). Nesse sentido, os que escreviam nas gazetas não pretendiam ser somente ouvidos entre os doutos e filósofos, mas também entre os praticantes da política econômica e os usufrutuários delas, como os comerciantes portugueses e brasileiros. Obviamente, as sociedades maçônicas exerceram um papel importante, no sentido de congregar os que se interessavam pela economia política do império português; no entanto, o espraiamento das ideias liberais foi muito maior em razão de sua veiculação às gazetas.

Por fim, uma última ambiguidade do pensamento liberal de Hipólito derivou de sua relação muito próxima com a maçonaria. Duas visões de sociedade chocavam-se: uma ideal, fundada na igualdade, e outra concreta, organizada segundo as hierarquias pensadas pela maçonaria com base no modelo medieval de corporações de ofício, o que demonstra a forte relação do pensamento de Hipólito com a sociedade estratificada do Antigo Regime. As sociedades livres não podiam contar com qualquer forma de despotismo, como a escravidão, mas não eram, necessariamente, sociedades livres de qualquer princípio hierárquico. Muito pelo contrário, as fidelidades entre um pedreiro-livre e um aristocrata de nível superior deveriam ser visadas e preservadas.

Para nós, essas ambiguidades e contradições do liberalismo português de finais do século XVIII e primórdios do século XIX explicam-se pelo fato de que as ideias econômicas liberais teriam chegado aos impérios ibéricos sem as suas correspondentes 
políticas. Segundo Gabriel Paquette, havia profundas contradições no uso das ideias liberais nos impérios ibéricos e, muitas vezes, tem-se a impressão de que o liberalismo econômico antecipa-se ao político nas Américas Portuguesa e Espanhola. (PAQUETTE, 2013: 123-124). A intenção dos reformadores ilustrados portugueses não era a de fazer uma revolução análoga à francesa no Império português, mas a de melhorar o funcionamento deste a partir dos princípios de livre comércio. O ideário liberal - se é que é possível definir um único - não foi aceito sem ressalvas pelos ilustrados luso-brasileiros. Sua dimensão econômica era útil, em particular nas relações com as potências dominantes, como Inglaterra e França, mas sua dimensão social era perigosa: poderia resultar em um novo Haiti. Daí ser mais interessante e adequado para os reformadores portugueses o liberalismo pensado pela maçonaria, que combinava algumas das liberdades de comércio, por exemplo, o fim dos monopólios, com uma sociedade hierarquizada em novos termos, tendo os maçons por ponto de convergência.

Segundo Paulo Roberto de Almeida, ao concluir sua obra em 1822, Hipólito deixava uma espécie de legado dessa economia política e de suas ambiguidades no interior do império português. Ao mesmo tempo em que traçava a decadência de Portugal, anunciava a ascensão de um novo Estado, o Brasil, assentado em princípios que não somente o da liberdade de comércio, mas também os do progresso industrial, duas linhas de desenvolvimento histórico antagônicas na visão de Hipólito da Costa:

Quanto às relações comerciais com as demais nações, quer haja quer não a formalidade do reconhecimento [do novo Estado brasileiro independente], o governo do Brasil terá sempre o direito de prescrever aos estrangeiros que lá forem comerciar os regulamentos que bem lhe aprouver; e seguramente a prudência desses regulamentos equivale bem, quando não seja preferível, aos onerosos tratados de comércio, com que muitas vezes as nações ligam, sem o saberem, as mãos da indústria (Correio Braziliense, vol. 29, jul 1822: 608).

É nesse sentido industrializante, e não somente como uma contraparte de um tratado de livre-comércio, que o Brasil poderia efetivamente se conceber como um país livre. Em 1822, Hipólito encerrava a última edição do Correio Braziliense com a seguinte frase: "O Brasil quer ser livre; pode ser livre; é já livre". 


\section{Conclusão}

Este artigo representa uma primeira aproximação em relação às ideias econômicas disseminadas pela vasta obra de Hipólito José da Costa. Percebemos, ao longo do estudo, que os escritos do Correio Braziliense precisam dialogar com outros trabalhos do autor, no sentido de que suas ideias econômicas se façam compreender plenamente, inclusive considerando o conteúdo político que lhe é bastante característico.

Dessa maneira, um primeiro ponto de diálogo é com a experiência de viagem do autor pelos Estados Unidos. Dessa experiência de viagem, o autor retirou argumentos muito importantes contra a escravidão, que não se faziam sentir até então dentro da geração de 1790, mais preocupada com a reforma do império (o que significava deixar o tráfico negreiro e a escravidão intocados), do que com sua transformação radical. A possibilidade de o imigrante substituir o escravo foi reforçada pelo uso da maquinaria na lavoura que, aumentando imensamente a produtividade do trabalho, tornava o trabalho compulsório um disparate.

Dessa maneira, a industrialização se configura, na obra de Hipólito da Costa, em um caminho para a libertação humana. Também contra outras formas de escravização, como a imposta pela Inquisição, que era vista como uma escravidão religiosa, levantavase o verbo sempre mordaz de Hipólito. A partir de sua Narrativa da perseguição, publicada em 1805, o autor reforçava seu liberalismo maçônico, empreendendo uma escalada contra o Estado absolutista e a Igreja, seu principal braço.

Finalmente, um último ponto de diálogo para a compreensão das ideias econômicas de Hipólito é com as obras de economia política que traduz e que publica, como Os princípios de economia política de Sismondi. Essa economia política permite a Hipólito fundamentar ideias aparentemente contraditórias, como o livre-comércio e a política alfandegária visando à industrialização, e que perfizeram, juntas, um liberalismo bastante sui generis.

Nesse sentido, o contorno das ideias econômicas de Hipólito é muito mais prático e político do que propriamente teórico. O caráter pragmático das ideias de Hipólito da Costa, o que o aproxima de um mercantilista ou de um protecionista, não sendo nem um, nem outro, vê-se pela própria divisão do Correio Braziliense, que, no fundo, remete a práticas políticas. Na primeira seção, a dos Tratados, mostrava-se efetivamente o que os estadistas discutiam em torno de conflitos, guerras e territórios. $\mathrm{Na} 2^{\mathrm{a}}$ seção, artes e 
comércio, Hipólito expunha os tratados de comércio. Na seção de Literatura e Ciências, o autor comentava algumas obras que eram de economia política na maior parte das vezes. Finalmente, na seção Miscelânea, além de assuntos vários, o autor tecia seus próprios comentários sobre os temas.

O liberalismo, um ideário flexível, tem também uma dimensão muito particular em Hipólito. Embora concordasse com o fim dos monopólios, o autor utilizou de sua experiência nos Estados Unidos e na Inglaterra para falar a respeito das limitações das políticas de livre-comércio. As nações apresentavam diferenças entre si e não era de se ignorar (segundo o próprio Hipólito da Costa) que a Inglaterra, que era a propagadora de tais ideias, fosse também a nação que mais lucrava com o comércio de suas colônias. Isso levou o autor a advogar pela causa da proteção tarifária (ideia já colocada no Diário da Filadélfia) e da industrialização nacional. No caso do Brasil, não seria de se desconsiderar um grande potencial de desenvolvimento das manufaturas a transferência da capital para o interior do país.

O autor também foi bastante original ao expressar uma concepção de nação que aos poucos se desvinculava da concepção imperial ou, ao menos, era-lhe complementar. Até então, os autores falavam em reino ou nação para Portugal, mas não para o Brasil. É de se notar inclusive um termo muito particular, "brasiliense", que só poderia ter sido cunhado por alguém que, nascido na colônia do Sacramento, sentia-se diferente no império português.

\section{Fontes}

COSTA, Hipólito J. da (2004 [1798-1799]). Diário da minha viagem para Filadélfia, 1789-1799. Brasília, Edições do Senado Federal, Volume 33. (1808-1822). Correio Braziliense, ou, Armazém literário. Londres. Oficina do Correio Brasiliense. ed. fac-similar, vols. 1 a 29.

(2001 [1811]) Narrativa da perseguição. Brasília, Fundação Assis Chauteaubriand.

(1811). Nova gramática portuguesa e inglesa. Londres (reeditada em 1825 por J. Collingwood). 


\section{Referências Bibliográficas}

ALEXANDRE, Valentim Alexandre (1993). Os sentidos do Império: questão nacional e questão colonial na crise do Antigo Regime Português. Coleção Biblioteca das Ciências do Homem Porto. Porto, Edições Afrontamento.

ALMEIDA, Paulo Roberto de (2002). O nascimento do pensamento econômico brasileiro. In: DINES, Alberto \& LUSTOSA, Isabel. (Orgs). Correio Braziliense ou Armazém Literário, vol. 30, t. 1, Estudos. São Paulo: Imprensa Oficial, pp. 323370.

ARRUDA, José Jobson de Andrade (2008). Uma Colônia entre dois impérios: a abertura dos portos brasileiros (1800-1808). Bauru / SP: EDUSC.

BIBLIOTECA DO EXÉRCITO (1985). Hipólito da Costa: ideias e ideais. Volume 540.

BIBLIOTECA NACIONAL (1974). Hipólito José da Costa e a imprensa no Brasil. Catálogo da exposição organizada pela sessão de exposições. Rio de Janeiro: Biblioteca Nacional: Divisão de Publicações e Divulgação.

BARATA, Alexandre Mansur (2006). Maçonaria, sociabilidade ilustrada $e$ Independência do Brasil (1790-1822). São Paulo; Juiz de Fora, Annablume: Editora da UFJF.

DIAS, Graça da Silva \& DIAS, José Sebastião da Silva (1980). Os primórdios da maçonaria em Portugal. Lisboa: Instituto Nacional de Investigação Científica, 2 vols.

MARQUES, Antonio Henrique de Oliveira (1990-1997). História da maçonaria em Portugal. Lisboa: Editorial Presença, 3 vols.

BOTO, Carlota (2010). A dimensão iluminista da reforma pombalina dos estudos: das primeiras letras à universidade". Revista Brasileira de Educação (online), v. 15 n. 44, pp. 282-299.

BUVAlOVAS, Thais Helena dos Santos (2011). Hipólito da Costa na FiladélfiaImprensa, maçonaria e cultura política na viagem de um ilustrado luso-brasileiro aos Estados Unidos (1798-1800). São Paulo: Hucitec Editora.

CALMON, Pedro (1974). Apresentação. Hipólito José da Costa e a imprensa no Brasil. Catálogo de exposição. Rio de Janeiro: Biblioteca Nacional, sn.

CARDOSO, José Luís (2001). "Nas malhas do Império: a economia política e a política colonial de D. Rodrigo de Souza Coutinho". In A economia política e os dilemas do Império luso-brasileiro (1790-1822). Lisboa: Comissão Nacional para as Comemorações dos Descobrimentos Portugueses.

CARDOSO, José Luís (2009). Free trade, political economy and the birth of a new economic nation, Brazil, 1808-1810. Revista de Historia Económica - Journal of Iberian and Latin American Economic History, Vol. 27, 2, 183-204.

CARNEIRO, Ana; DIOGO, Maria Paula; SIMÕES, Ana (2000). "Enlightenment science in Portugal: the estrangeirados and their communication networks". In Social studies of Science, vol. 30, n. 4, pp. $591-619$.

CASTRO, Therezinha de (1985). Hipólito da Costa, ideias e ideais. Rio de Janeiro: Record.

CORTESÃO, Jaime (1956). "Castiços e estrangeirados". In CORTESÃO, Jaime. Alexandre de Gusmão e o Tratado de Madrid, vol. 2. Rio de Janeiro, Ministério das Relações Exteriores/Instituto Rio Branco, 1956.

COSTA, Wilma Peres \& OLIVEIRA, Cecília H. Salles de (2007) (orgs.). De um império a outro-formação do Brasil séculos XVIII e XIX. São Paulo: Hucitec. 
COUTINHO, Mauricio Chalfin (2016). "Silva Lisboa on free trade and slave labor". In CUNHA, Alexandre Mendes \& SUPRINVAK Carlos Eduardo (eds). The Political Economy of Latin American Independence. Routledge.

CUNHA, Alexandre Mendes \& SUPRINYAK, Carlos Eduardo (eds) (2017). The Political Economy of Latin American Independence. New York: Routledge, ch. 4.

DIAS, Maria Odila de Silva (1972). A interiorização da metrópole (1808-1853). In: MOTA, Carlos G. (org.). 1822: Dimensões. São Paulo: Perspectiva, pp. 160-184.

DINES, Alberto (2002). Luz e trevas. Estrangeirados e a Inquisição. In DINES, Alberto e LUSTOSA, Isabel. (orgs.) Correio Braziliense ou Armazém Literário, vol. 30, t. 1, Estudos. São Paulo: Imprensa Oficial, pp. 437-468.

DOURADO, Mecenas (1957). Hipólito da Costa e o Correio Brasiliense. Rio de Janeiro: Biblioteca do Exército, 2 tomos.

DUTRA, Eliana de Freitas \& MOLLIER, Jean-Yves (2006). Política, nação e edição - o lugar dos impressos na construção da vida política: Brasil, Europa e Américas nos séculos XVIII-XX. São Paulo: Annablume.

FALCON, Francisco C (1995). "O iluminismo e os estrangeirados em Portugal”. In Américas, n. 1. São Paulo: UNIMARCO, pp. 31-46.

FERNANDES, Ana Claudia (2009). A revolução de Pernambuco nas páginas do Correio Braziliense e do Correo del Orinoco: linguagens, conceitos e projetos políticos em tempos de independência (1817-1820). Almanack Braziliense, n.09, pp. 144-153 (online). Disponível em: http://dx.doi.org/10.11606/issn.1808-8139.v0i9p144153. Acesso em: 01 jul. 2016.

FERREIRA, João Pedro Rosa (1988). O jornalismo na emigração. Ideologia e política no Correio Braziliense, 1808-1822. Lisboa, Instituto Nacional de Investigação Científica, Centro de História da Cultura da Universidade Nova de Lisboa.

GALVÃO, Joaquim de Santo Agostinho Brito (1809). Reflexões feitas em abono da verdade sobre os números do Correio Braziliense, Lisboa, Impressão Régia.

HOBSBAWM, Eric (1990). Nações e nacionalismo desde 1780: programa, mito e realidade. Trad. Prot. Rio de Janeiro: Paz e Terra.

LUSTOSA, Isabel (2000). Insultos impressos: a guerra dos jornalistas na Independência (1821-1823). São Paulo: Cia das Letras. . (2008). His Royal Highness e Mr. da Costa. In DINES, Alberto \& LUSTOSA, Isabel. (Orgs). Correio Braziliense ou Armazém Literário, vol. 30, t. 1, Estudos. São Paulo: Imprensa Oficial, pp. 15-60.

LYRA, Maria de Lourdes Viana e (1994). A Utopia do Poderoso Império. Rio de Janeiro: Sette Letras.

MACEDO, Riopardense de (1975). Hipólito da Costa e o Universo da Liberdade. Porto Alegre: Ed. ARI / Sulina.

MACEDO, Jorge Borges de (1974). ' Estrangeirados: um conceito a rever. In Bracara Augusta, Vol. 28, 179-202.

MAXWELL, Kenneth (1998). A Geração de 1790 e a ideia do Império Luso-Brasileiro. In: Chocolate, piratas e outros malandros - Ensaios Tropicais. Rio de Janeiro: Paz e Terra, pp. 157- 191.

MAXWELL, Kenneth (1978), A Devassa da Devassa: a Inconfidência Mineira, BrasilPortugal, 1750-1808. Rio de Janeiro: Paz e Terra.

MARTINS, António Coimbra (1965). Estrangeirados. In SERRÃO, Joel, org., Dicionário de História de Portugal. Lisboa, Iniciativas Editoriais, pp. 122-129.

MARTINS, Décio Ruivo (2013). A faculdade de filosofia natural (1772-1911). In: FIOLHAIS, Carlos; SIMÕES, Carlota \& MARTINS, Décio (eds). História da 
Ciência na Universidade de Coimbra (1772-1933). Coimbra; Imprensa da Universidade de Coimbra, pp.63-115.

MOLINA, Matías M. (2015). História dos jornais no Brasil, vol. 1: Da era colonial à Regência (1500-1840). Cia das Letras. São Paulo: Cia das Letras.

MOREL, Marcos (2002). Entre a estrela e o satélite. In: DINES, Alberto \& LUSTOSA, Isabel (Orgs). Correio Braziliense ou Armazém Literário, vol. 30, t. 1, Estudos. São Paulo: Imprensa Oficial, pp.269-320.

MUNARO, Luís Francisco (2013). "O jornalismo luso-brasileiro em Londres (18081822)". Tese de doutorado. Niterói, UFF, 2013.

NEVES, Guilherme Pereira das (1995). Do Império luso-brasileiro ao império do Brasil (1789-1822). Ler História, Lisboa, v.27-28, pp.75-102.

NOVAIS, Fernando (2005). Aproximações: estudos de história e historiografia. São Paulo: Cosac Naify. . (1979). Portugal e Brasil na crise do antigo sistema colonial (1777-1808). São Paulo: Hucitec.

PAQUETTE, Gabriel (2013). Imperial Portugal in the Age of Atlantic Revolutions. The Luso-Brazilian World, c. 1770-1850. Cambridge, Cambridge University Press.

PAULA, Sérgio Goes (2001) (org.). Hipólito José da Costa. Coleção Formadores do Brasil. São Paulo: Editora 34.

.; Patricia Souza (2002). Os paradoxos da liberdade. In: DINES, Alberto \& LUSTOSA, Isabel (Orgs). Correio Braziliense ou Armazém Literário, vol. 30, t. 1, Estudos. São Paulo: Imprensa Oficial, pp. 111-160.

PEREIRA, José Luiz de Moura (1996). Hipólito da Costa - O Patriarca da Imprensa Brasileira, Studio Z, BSB.

PEREIRA, Miriam Halpern (2013). Crown, Empire and Nation (1807-1834). In Ejournal of Portuguese History. Vol. 11, n. 1 (2013).

QUEVEDO, Raul (1997). Em Nome da Liberdade - A saga de Hipólito da Costa. Pelotas: UFPEL.

RIZZINI, Carlos (1957). Hipólito da Costa e o Correio Braziliense. São Paulo: Companhia Editora Nacional.

ROSANVALLON, Pierre (2002). O liberalismo econômico-história da ideia de mercado. Trad. Antonio Penalves Rocha. Bauru, SP: EDUSC.

SOBRINHO, Barbosa Lima (1977) (org.). Antologia do Correio Brasiliense. Rio de Janeiro: Cátedra.

. (1996) (org.). Hipólito da Costa: pioneiro da Independência doBrasil. Brasília: Fundação Assis Chateaubriand/Verano.

TENGARRINHA, José (2002). O jornalismo da primeira emigração em Londres. In: DINES, Alberto \& LUSTOSA, Isabel. (Orgs). Correio Braziliense ou Armazém Literário, vol. 30, t. 1, Estudos. São Paulo: Imprensa Oficial, pp. 219-258.

SILVA, Maria Beatriz Nizza da, MARQUES, A. H. de Oliveira e SERRÃO, Joel (1986). O Império Luso-Brasileiro - 1750-1822. Lisboa: Editorial Estampa. 
Artigo recebido em 30 de agosto de 2016.

Aprovado em 25 de março de 2017.

DOI: 10.12957/intellectus.2017.25337 